\title{
Investigating mental and physical disorders associated with COVID-19 in online health forums
}

Rashmi Patel $^{* 1,2}$, Fabrizio Smeraldi ${ }^{* 3,4,6}$, Maryam Abdollahyan ${ }^{5}$, Jessica Irving ${ }^{1}$, and Conrad Bessant $^{3,4,6}$

1. King's College London (Institute of Psychiatry, Psychology and Neuroscience), London, UK

2. South London and Maudsley NHS Foundation Trust, London, UK

3. Queen Mary University of London, UK

4. Memobine Ltd, Cambridge, UK

5. Barts Cancer Institute, London, UK

6. The Alan Turing Institute, London, UK

* Equal contribution to authorship

Manuscript word count: 3,216

Abstract word count: 220

Keywords: COVID-19, comorbidity, real world data, social media, natural language processing 
Competing interests: All authors have completed the ICMJE uniform disclosure form at www.icmje.org/coi_disclosure.pdf and declare: RP has received funds from Janssen, Induction Healthcare and Holmusk outside the current study. The other authors declare no competing interests.

Author contributions: The study was conceived by RP and FS. Data extraction and statistical analysis were performed by FS, MA and CB. Reporting of findings were carried out by RP and JI. All authors (RP, FS, MA, JI and CB) contributed to study design, manuscript preparation and approved the final version. FS is guarantor.

Ethics approval: Data for this study were drawn from publicly available online health forums and extracted in aggregate form for secondary data analysis rather than at individual user level. No individual user level data were retained, making it impossible to obtain informed consent. However, users were aware that their data were available for anyone to view online by virtue of contributing to publicly available online health forums. The data were analysed using the computing infrastructure based at Queen Mary University of London (QMUL) which employs a two-layer security model to maintain data privacy. QMUL is registered as a data controller with the Information Commissioner's Office (ICO; registration number: Z5507327), which covers all research activities undertaken at the university.

Source of funding: RP has received support from a Medical Research Council (MRC) Health Data Research UK Fellowship (MR/S003118/1) and a Starter Grant for Clinical Lecturers (SGL015/1020) supported by the Academy of Medical Sciences, The Wellcome Trust, MRC, British Heart Foundation, Arthritis Research UK, the Royal College of Physicians and Diabetes UK. FS and CB were partly funded by an Alan Turing Institute (ATI) Fellowship and by an EPSRC COVID-19 Rapid Response Impact Acceleration Fund. Computational resources were partly funded by a Microsoft Azure Sponsorship through the ATI.

Role of funder: The views expressed are those of the authors and not necessarily those of the funders. The funders had no role in the design and conduct of the study; collection, management, analysis, and interpretation of the data; preparation, review, or approval of the manuscript; and decision to submit the manuscript for publication.

Data sharing: Given licensing and privacy issues, it is not possible to release the dataset generated from the online health forums investigated in this study. However, we welcome collaboration with other researchers and healthcare policy makers. Anyone interested in accessing the aggregate data and data analysis code should contact the guarantor (f.smeraldi@qmul.ac.uk). 


\begin{abstract}
Objectives: Online health forums provide rich and untapped real-time data on population health. Through novel data extraction and natural language processing (NLP) techniques, we characterise the evolution of mental and physical health concerns relating to the COVID-19 pandemic among online health forum users.
\end{abstract}

Setting and design: We obtained data from 739,434 posts by 53,134 unique users of three leading online health forums: HealthBoards, Inspire and HealthUnlocked, from the period $1^{\text {st }}$ January 2020 to $31^{\text {st }}$ May 2020. Using NLP, we analysed the content of posts related to COVID-19.

\title{
Primary outcome measures:
}

(i) Proportion of forum posts containing COVID-19 keywords

(ii) Proportion of forum users making their very first post about COVID-19

(iii) Number of COVID-19 related posts containing content related to physical and mental health comorbidities

Results: Posts discussing COVID-19 and related comorbid disorders spiked in early- to midMarch around the time of global implementation of lockdowns prompting a large number of users to post on online health forums for the first time. The pandemic and corresponding public response has had a significant impact on posters' queries regarding mental health.

Conclusions: We demonstrate it is feasible to characterise the content of online health forum user posts regarding COVID-19 and measure changes over time. Social media data sources such as online health forums can be harnessed to strengthen population-level mental health surveillance.

\section{Article Summary}

\section{Strengths and limitations of this study}

1. Analysing online health forum data using NLP revealed a substantial rise in activity which correlated with the onset of the COVID-19 pandemic.

2. Real-time data sources such as online health forums are essential for monitoring fluctuating population health and tailoring responses to daily pressures.

3. It is not yet possible to establish COVID-19 status or whether concerned posters have pre-existing mental or physical health issues, are recovered, or have become unwell for the first time.

4. Online health forums are help-seeking forums, which introduces self-selection bias. 


\section{Introduction}

Measures to tackle the COVID-19 pandemic have resulted in unprecedented societal restrictions worldwide. The mental health impacts of these measures and accompanying socioeconomic stressors are likely to be extensive; identifying and quantifying these impacts are now an urgent priority.[1] For example, social distancing restrictions make it harder to maintain regular contact between individuals and their friends and family as well as health and social care professionals. Furthermore, the psychological and emotional burden of the pandemic (and its consequences) may increase risk of relapse or worsen existing mental health disorders. Conversely, mental disorders can increase susceptibility to infections.[2,3]

Real-world data from online resources may be extracted using natural language processing (NLP) techniques to provide automated, population-level health surveillance. These methods can be used to rapidly ascertain discussion related to COVID-19 and associated symptoms and comorbidities. NLP has previously been used to identify medically relevant information from web pages and analyse extracted text.[4,5] Applying these techniques to real world data sources such as social media and online forums may be used to supplement active data collection from participants in prospective observational research. Recent studies have applied this approach to Twitter, Facebook and Reddit data to forecast the emergence of depression and post-traumatic stress disorder,[6] predict depression in the general population,[7] identify mothers at risk of postpartum depression,[8] and investigate suicidal ideation.[9]

While social media platforms such as Twitter, Facebook and Reddit are commonly used, other internet resources such as online health forums have so far been neglected. Online health forums are enriched for health information and receive millions of posts each year, therefore providing untapped reservoirs of healthcare data at population level.

In a recent proof-of-concept study we demonstrated that online health forums can be extracted to detect health discussion trends that correlate with real-life events.[10] Here, we use the same technology to analyse online health forum data discussing mental and physical health problems associated with the COVID-19 pandemic. We use NLP techniques to extract data from online health forum posts related to the COVID-19 pandemic, references to specific comorbid illnesses, and their direct and indirect impacts on mental or physical health. 


\section{Methods}

\section{Study Design and Setting}

We obtained data from online health forums using NLP. Online forums are discussion websites hosted on the internet where people hold conversations in the form of posted messages. A single conversation is called a thread. Threads are chains of posts identified within a forum by a title and an individual URL. Clicking on the thread title opens the thread which contains one or more posts which may be from the same user who started the thread (i.e. the original poster) or different users who have replied within the thread. In this study, we analysed text data in thread titles and in individual posts within a thread. We analysed posts written in English only. Depending on the forum's settings, users can be anonymous or have to register with the forum to post messages, with most users opting not to use personally identifiable information to register their account. Registration may not be required for readonly access. Most forums recommend that users do not use personally identifiable information when posting. Online health forums specifically cover health topics and offer peer support for various health conditions.

We collected data from three major online health forums posted from $1^{\text {st }}$ January 2020 to $31^{\text {st }}$ May 2020: HealthBoards (www.healthboards.com), Inspire (www.inspire.com) and HealthUnlocked (www.healthunlocked.com). These forums were chosen on the basis that they have global user coverage, include subforums on several aspects of healthcare, have a large user base contributing to regular activity on the forum, and are feasible to extract information from using NLP.

HealthBoards was founded in California, USA in 1997 and offers patient to patient health support. Inspire, founded in 2005, is a US healthcare social network managing online support groups for patients and caregivers. HealthUnlocked is a British online health forum launched in 2011 with a similar offering to HealthBoards and Inspire. Registration and participation in all three forums are free of charge to users.

\section{Analysis Using NLP}

\section{Definition of search terms}

To investigate the potential impact of COVID-19 on users posting in online health forums, we classified threads and posts using keywords related to the COVID-19 pandemic and various groups of case-insensitive keywords relating to medical treatment in an intensive care unit or physical symptoms as a direct consequence of COVID-19 infection or mental health symptoms as a consequence of measures in response to the pandemic.

Search terms used to identify whether a thread or post was related to COVID-19 were 'covid', 'covid-19', 'coronavirus', 'corona', 'sars-cov-2', 'sars-2', 'shielding', 'pandemic*', 'vulnerable', 'quarantine', 'lockdown', 'distancing', 'isolation', 'isolating' where * indicates a wildcard search term. 
Table 1 provides the final keywords used to search posts within COVID-19 related threads; the Python coded search terms are provided in Supplementary Tables 2 and 3. We tested the specificity of keywords by searching for matches occurring before $1^{\text {st }}$ January 2020 . For threads, these were matches in the title and URL, while for posts, these were matches in the entire text (see Extracting and matching keywords below). Term incidence and excluded keywords are provided in Supplementary Table 5.

\section{Data pre-processing}

Data obtained from different online health forums come in various formats. We standardised and normalised the data before analysing them. This included normalisation of Unicode strings and whitespace characters, standardisation of date and time, and standardisation of location through the GeoNames.org database.

\section{Extracting and matching keywords}

We extracted the keywords in thread titles and post content using lemmatisation. For flexibility and efficiency, search terms in posts and thread titles were matched using regular expressions that accounted for both inflection and common spelling variants. Matching was case-insensitive and limited to whole words in the post content and thread title; when matching thread URLs, parts containing words were considered. To prevent spurious matches, words shorter than four letters (e.g. ICU) were considered valid matches only if they were delimited by non-word characters.

Analysis of COVID-19 threads to identify changes in COVID-19 related user activity and physical and mental health associations over time

We identified the users contributing to a COVID-19 related thread in a given week. We then retrieved all the other posts made by the same authors in the previous, same and subsequent calendar weeks. We scanned such posts for physical symptom, mental health symptom or intensive care keywords as defined in Table 1, and recorded whether each of these topics was mentioned by the author during the time window. We performed this analysis to establish variations in the prevalence of concerns relating to physical symptom, mental health symptom and intensive care keywords over the course of the pandemic during 2020. Weekly counts were measured each Sunday for the previous week.

\section{Analysis of thread titles}

We inspected thread titles to identify how many mentioned a comorbidity in the title. We searched for terms related to autoimmune disorders, mental disorders or worry, cancer, cardiovascular problems or stroke, and diabetes as listed in Table 2; the Python coded search terms are provided in Supplementary Table 4.

\section{Analysis of first-time posters in a COVID-19 related thread}

We analysed the first ever post published by a user to determine the proportion of first-time posters who started out by contributing to a COVID-19 related thread. We performed this 
analysis to determine the degree to which new users were motivated to make their first post in relation to the COVID-19 pandemic and how this varied over time during 2020.

\section{Implementation and computation}

All descriptive analyses were performed using bespoke software written in Python. An outline of the coding approach employed is included in the Supplementary Material.

\section{Ethics and Data Sharing}

We consulted and adhered to internet research guidelines from the Association of Internet Researchers [11] and the British Psychological Society (BPS) [12] to inform study development.

All data have been provided in aggregate form to protect the privacy of forum users. As we analysed data in aggregate form, it was not possible to seek individual user consent. However, users were aware that their data were available for anyone to view online by virtue of contributing to publicly available online health forums. Of note, the BPS guidelines advise that "valid consent should be obtained where it cannot be reasonably argued that online data can be considered 'in the public domain' or that undisclosed usage is justified on scientific value grounds". This approach is consistent with similar studies examining healthcare related data from Twitter.[13,14]

QMUL is registered as a data controller with the Information Commissioner's Office (ICO; registration number: Z5507327), which covers all research activities undertaken at the university. All data were analysed on QMUL IT facilities, which employs a two-layer security model as per their security policy.

Given licensing and privacy issues, it is not possible to publicly release the aggregate dataset generated from the three online health forums investigated. However, we welcome collaboration with other researchers and healthcare policy makers. Anyone interested in accessing the aggregate data and data analysis code should contact the guarantor (f.smeraldi@qmul.ac.uk).

\section{Patient and public involvement}

As the data were analysed in aggregate form it was not possible to involve individual forum users in the design or conduct of the study. 


\section{Results}

\section{Related posts and active threads}

HealthUnlocked was the most frequently used forum accounting for $97 \%$ of overall posts and $97 \%$ of posts mentioning COVID-19 in the thread title or post content during the study period (Table 3).

Weekly post count for HealthUnlocked peaked in mid-March. Post count for Inspire declined sharply in the last two weeks of March. Post count for HealthBoards declined slowly across the entirety of the observation period (Supplementary Figure 1).

Across all three forums, there were a total of 3,342 threads containing a COVID-19 keyword within the thread title or URL. These contained a total of 44,894 posts during the study period ( $1^{\text {st }}$ January 2020 to $31^{\text {st }}$ May 2020). A total of 35,581 posts (whether in COVID-19 related threads or otherwise) contained a COVID-19 keyword during the study period. The proportion of posts containing COVID-19 keywords increased rapidly across all forums in early March (Supplementary Figures 2 and 3), corresponding with the World Health Organisation's declaration of COVID-19 as a pandemic on $11^{\text {th }}$ March 2020. The smaller online forums (Inspire and HealthBoards) had a greater peak in percentage of total posts containing COVID-19 keywords. The total number of posts containing COVID-19 search terms declined from mid-April onwards.

For quite a long period, most posts about COVID-19 (over 90\% at the beginning of the observation period, and remaining above $50 \%$ until the week ending $29^{\text {th }}$ March) were written by users who had not yet posted on the topic. By the end of the observation period, the percentage of weekly posts in COVID-19 threads written by new entrants to the discussion reduced to a still quite sizeable $30 \%$. While many of these users may have posted before on the forum about other topics, Supplementary Figure 4 presents the proportion of posters whose very first post to a forum appeared in a COVID-19 related thread. This figure peaked above $20 \%$ in the week ending $22^{\text {nd }}$ March. Considering that these forums have a very broad spectrum, this is a remarkably high fraction. It includes both new joiners and users who were previously silent members of the forums, possibly for a long time (so-called "lurkers"), and who may have been spurred into a more active role by the pandemic.

\section{Thread title analysis}

Over a quarter of COVID-19 related thread titles mentioned another condition of interest (Table 4). After cancer and autoimmune diseases, mental health represented a major area of concern for online health forum users posting about COVID-19, comparable to respiratory and circulatory diseases (Table 2). Around $0.5 \%$ of thread titles mentioned two or more comorbidities.

User analysis

Posts in threads related to COVID-19 were analysed to determine the number of users contributing in each given week. For each active user, all posts in the previous, same and 
medRxiv preprint doi: https://doi.org/10.1101/2020.12.14.20248155; this version posted December 16, 2020. The copyright holder for this preprint (which was not certified by peer review) is the author/funder, who has granted medRxiv a license to display the preprint in perpetuity.

It is made available under a CC-BY 4.0 International license .

Investigating mental and physical disorders associated with COVID-19 in online health forums

following calendar weeks were scanned irrespective of thread for mentions of physical symptom, mental health symptom or intensive care keywords. The number of active users mentioning each of these concerns peaked in the week ending $22^{\text {nd }}$ March and subsequently declined but still remained elevated above the January baseline. In particular, users discussing mental health outnumbered users mentioning the other topics (Figure 1). 


\section{Discussion}

Using a novel technique to analyse data from online health forums, we found a marked increase in posts related to COVID-19 across the observation period of $1^{\text {st }}$ January 2020 to $31^{\text {st }}$ May 2020. The frequency of these posts increased rapidly in early March 2020 corresponding with the World Health Organisation's declaration of COVID-19 as a pandemic.

During this period, we found mental health symptom keywords were most frequently mentioned by authors of COVID-19 related posts (either contextually or in separate messages), followed by physical symptoms and intensive care keywords, suggesting that the pandemic and public health response to it has had a significant impact on posters' concerns regarding mental health. The marked increase in mental health symptom related posts in early March, when the WHO declared the COVID-19 pandemic, correlates with preliminary worldwide data that show increases in anxiety and depression in response to the outbreak.

The mental health impacts of COVID-19 and associated physical distancing restrictions are likely to be extensive and wide-reaching. There is a growing body of evidence supporting the neuropsychiatric effects of coronavirus infections.[15] Restrictions fuel socioeconomic stressors such as unemployment, loneliness and financial burden, which are all implicated in the development of mental ill health.[16] Increased rates of bereavement, newfound caring responsibilities and interruptions to education are likely to be particularly stressful to children and young adults.[17]

A preliminary survey of 3,545 German respondents found evidence of substantial mental health burden from travel and physical distancing restrictions, including increased levels of stress, anxiety, depressive symptoms, sleep disturbance and irritability.[18] Worsening mental health has been confirmed in samples with both pre- and post-pandemic information for direct comparison: The Avon Longitudinal Study of Parents and Children (ALSPAC) study found probable anxiety disorder doubled compared to pre-pandemic sizes $(26 \%$ vs $13 \%$ ) and lower wellbeing, particularly in young people, women and those with pre-existing conditions.[19] The literature on social media mining for COVID-19 mental health related trends is limited. A study analysing sentiment evolution trends of four emotions across Twitter - fear, anger, sadness, joy - has been able to identify developing shared distress, and topics of interest relating to those emotions.[20]

Our findings also suggest that mental and physical health concerns documented in online forum posts have levelled off following their peak in March 2020. The number of users active in COVID-19 threads who also wrote posts concerning mental health symptoms reduced from their peak in March of 1,355 (per week) to 253 by the end of the observation period (compared to a mean number of 30 per week in January), suggesting that as time went on most users had begun to adjust to the consequences of the pandemic. Other NLP studies have also identified a similar trend. An analysis of 10 million Google searches within the United States found large shifts in mental health symptom searches linked to stay-at-home 
orders in the United States across the week commencing $16^{\text {th }}$ March 2020.[21] Searches for topics related to anxiety, negative thoughts about oneself and the future, insomnia and suicidal ideation dramatically increased prior to stay-at-home orders, levelling off upon the announcement of stay-at-home orders. These patterns were relatively unique to searches for mental health related information and not physical conditions.

Over the entire period, on average $4 \%$ of first-time posters (over $20 \%$ in the peak period) made their very first contribution to the forum in a COVID-19 related thread. Furthermore, $77 \%$ of COVID-19 threads were started by users who had never posted about the topic before, and chose to start out by creating their own thread. A certain degree of motivation is required to take someone to the point of making that first post on a forum, and also for starting a thread; our finding suggests that the pandemic is driving users to engage more actively in community forum services in times of uncertainty.

\section{Strengths and weaknesses}

Online health forums are an important source of real-world, real-time, population-level data on people living through the COVID-19 pandemic. Online health forums also afford users anonymity to discuss aspects of their experience they might otherwise have been embarrassed or fearful to disclose in identifiable forms of social media. We have demonstrated that it is possible to automate information extraction from these posts using natural language processing, providing access to a rich reservoir of previously untapped real-world data from health-specific online resources.

Our approach was able to automatically extract data from a large sample of over 53,000 unique users at a fraction of the cost of previous approaches that have relied on social media individual participant recruitment and manual review of posts generating sample sizes in the low hundreds.[7] Some studies screened users on Twitter via depression symptom questionnaires and used their tweets to train depression onset classifiers.[6,22] Analogous approaches have been used with Facebook data.[8]

Our study has some limitations. At present it is difficult to establish whether concerned posters have pre-existing mental or physical health issues, have experienced confirmed COVID-19 illness themselves, are recovered, or have become unwell for the first time. Online health forums are help-seeking communities; this introduces self-selection bias in which individuals from disadvantaged backgrounds who do not have IT equipment/network connection to access online resources are under-represented and our results are therefore not generalisable to the entire population. Furthermore, as these forums have worldwide coverage we cannot isolate trends to one geographic region. However, future work could utilise the location data (see Data pre-processing in Methods) to explore this avenue.

\section{Conclusions and future research}

Publicly accessible sources of real-world data, such as online health forums analysed in this study, can strengthen population-level physical and mental health surveillance and provide a rapid and inexpensive means to inform public healthcare policy. We found that the majority 
of posts in online forum data related to COVID-19 concerned features related to mental health and that the peak in frequency of posts corresponded with the early phase of the pandemic, indicating the significant impact of COVID-19 on the mental health of susceptible populations.

As the pandemic evolves, further research using online forum data could improve our understanding of the long-term consequences of COVID-19 infection [23] and the longerterm socioeconomic consequences of travel and physical distancing restrictions that have been employed in many countries to manage viral transmission.[24,25] Analysis of realworld data, including social media and online health forums, could provide a useful insight into attitudes and perceptions towards novel therapeutics. This will be crucial to maximising uptake of effective preventative approaches such as mask-wearing, physical distancing, hygiene measures and potential vaccines. 
It is made available under a CC-BY 4.0 International license .

Investigating mental and physical disorders associated with COVID-19 in online health forums

\section{References}

1 Holmes EA, O'Connor RC, Perry VH, et al. Multidisciplinary research priorities for the COVID-19 pandemic: a call for action for mental health science. The Lancet Psychiatry. 2020;7:547-60. doi:10.1016/S2215-0366(20)30168-1

2 Yao H, Chen J-H, Xu Y-F. Patients with mental health disorders in the COVID-19 epidemic. 2020. doi:10.1016/S2215-0366(20)30090-0

3 Seminog OO, Goldacre MJ. Risk of pneumonia and pneumococcal disease in people with severe mental illness: English record linkage studies. Thorax Published Online First: 2013. doi:10.1136/thoraxjnl-2012-202480

4 Landers RN, Brusso RC, Cavanaugh KJ, et al. A primer on theory-driven web scraping: Automatic extraction of big data from the internet for use in psychological research. Psychol Methods 2016;21:475-92. doi:10.1037/met0000081

5 Cambria E, White B. Jumping NLP curves: A review of natural language processing research. IEEE Comput. Intell. Mag. 2014;9:48-57. doi:10.1109/MCI.2014.2307227

6 Reece AG, Reagan AJ, Lix KLM, et al. Forecasting the onset and course of mental illness with Twitter data. Sci Rep 2017;7:1-11. doi:10.1038/s41598-017-12961-9

7 De Choudhury M, Gamon M, Counts S, et al. Predicting Depression via Social Media. 2013. www.aaai.org (accessed 23 Jun 2020).

8 De Choudhury M, Counts S, Horvitz E. Predicting postpartum changes in emotion and behavior via social media. In: Conference on Human Factors in Computing Systems Proceedings. New York, New York, USA: : ACM Press 2013. 3267-76. doi:10.1145/2470654.2466447

9 De Choudhury M, Kiciman E, Dredze M, et al. Discovering shifts to suicidal ideation from mental health content in social media. In: Conference on Human Factors in Computing Systems - Proceedings. Association for Computing Machinery 2016. 2098-110. doi:10.1145/2858036.2858207

10 Abdollahyan M, Smeraldi F, Patel R, et al. Investigating Comorbidity of Mental and Physical Disorders in Online Health Forums. Published Online First: 2020. doi:10.1145/3378184.3378195

11 Franzke AS, Bechmann A, Zimmer M, et al. Internet Research: Ethical Guidelines 3.0. 2020.

12 British Psychological Society. British Psychological Society Ethics Guidelines for Internetmediated Research. Br Psychol Soc Published Online First: 2017. doi:INF206/1.2013

13 Berry N, Lobban F, Belousov M, et al. \#WhyWeTweetMH: Understanding why people use Twitter to discuss mental health problems. J Med Internet Res Published Online First: 2017. doi:10.2196/jmir.6173

14 Sinha PP, Mahata D, Mishra R, et al. \#suicidal - A multipronged approach to identify and explore suicidal ideation in twitter. In: International Conference on Information and Knowledge Management, Proceedings. 2019. doi:10.1145/3357384.3358060

15 Rogers JP, Chesney E, Oliver D, et al. Psychiatric and neuropsychiatric presentations associated with severe coronavirus infections: a systematic review and meta-analysis with comparison to the COVID-19 pandemic. The Lancet Psychiatry 2020;7:611-27. doi:10.1016/S2215-0366(20)30203-0

16 Kawohl W, Nordt C. COVID-19, unemployment, and suicide. The Lancet Psychiatry. 2020;7:389-90. doi:10.1016/S2215-0366(20)30141-3

17 McManus S, Bebbington P, Jenkins R, et al. Mental health and wellbeing in England. 2016.

18 Jung S, Kneer J, Tillmann HC, et al. The German COVID-19 Survey on Mental Health: Primary Results. doi:10.1101/2020.05.06.20090340

19 F Kwong AS, Pearson M, Adams J, et al. Mental health during the COVID-19 pandemic in two longitudinal UK population cohorts 1. doi:10.1101/2020.06.16.20133116

20 Lwin MO, Lu J, Sheldenkar A, et al. Global Sentiments Surrounding the COVID-19 Pandemic on Twitter: Analysis of Twitter Trends. doi:10.2196/19447

21 Jacobson NC, Lekkas D, Price G, et al. Flattening the Mental Health Curve: COVID-19 Stayat-Home Orders Are Associated With Alterations in Mental Health Search Behavior in the 
medRxiv preprint doi: https://doi.org/10.1101/2020.12.14.20248155; this version posted December 16, 2020. The copyright holder for this preprint (which was not certified by peer review) is the author/funder, who has granted medRxiv a license to display the preprint in perpetuity.

It is made available under a CC-BY 4.0 International license .

Investigating mental and physical disorders associated with COVID-19 in online health forums

United States. JMIR Ment Heal Published Online First: 2020. doi:10.2196/19347

22 Tsugawa S, Kikuchi Y, Kishino F, et al. Recognizing depression from twitter activity. In: Conference on Human Factors in Computing Systems - Proceedings. New York, New York, USA: : Association for Computing Machinery 2015. 3187-96. doi:10.1145/2702123.2702280

23 Mahase E. Covid-19: What do we know about 'long covid'? BMJ. 2020;370. doi:10.1136/bmj.m2815

24 Rossi R, Socci V, Talevi D, et al. COVID-19 Pandemic and Lockdown Measures Impact on Mental Health Among the General Population in Italy. Front Psychiatry 2020;11. doi:10.3389/fpsyt.2020.00790

25 Veer IM, Riepenhausen A, Zerban M, et al. Psycho-social factors associated with mental resilience in the Corona lockdown. doi:10.31234/OSF.IO/4Z62T 
medRxiv preprint doi: https://doi.org/10.1101/2020.12.14.20248155; this version posted December 16, 2020. The copyright holder for this preprint (which was not certified by peer review) is the author/funder, who has granted medRxiv a license to display the preprint in perpetuity.

It is made available under a CC-BY 4.0 International license .

Investigating mental and physical disorders associated with COVID-19 in online health forums

Figure 1: Number of users making posts in threads related to COVID-19 which included physical symptoms, mental health symptoms or intensive care keywords

- Mental health symptoms - Physical Covid-19 symptoms - Intensive care

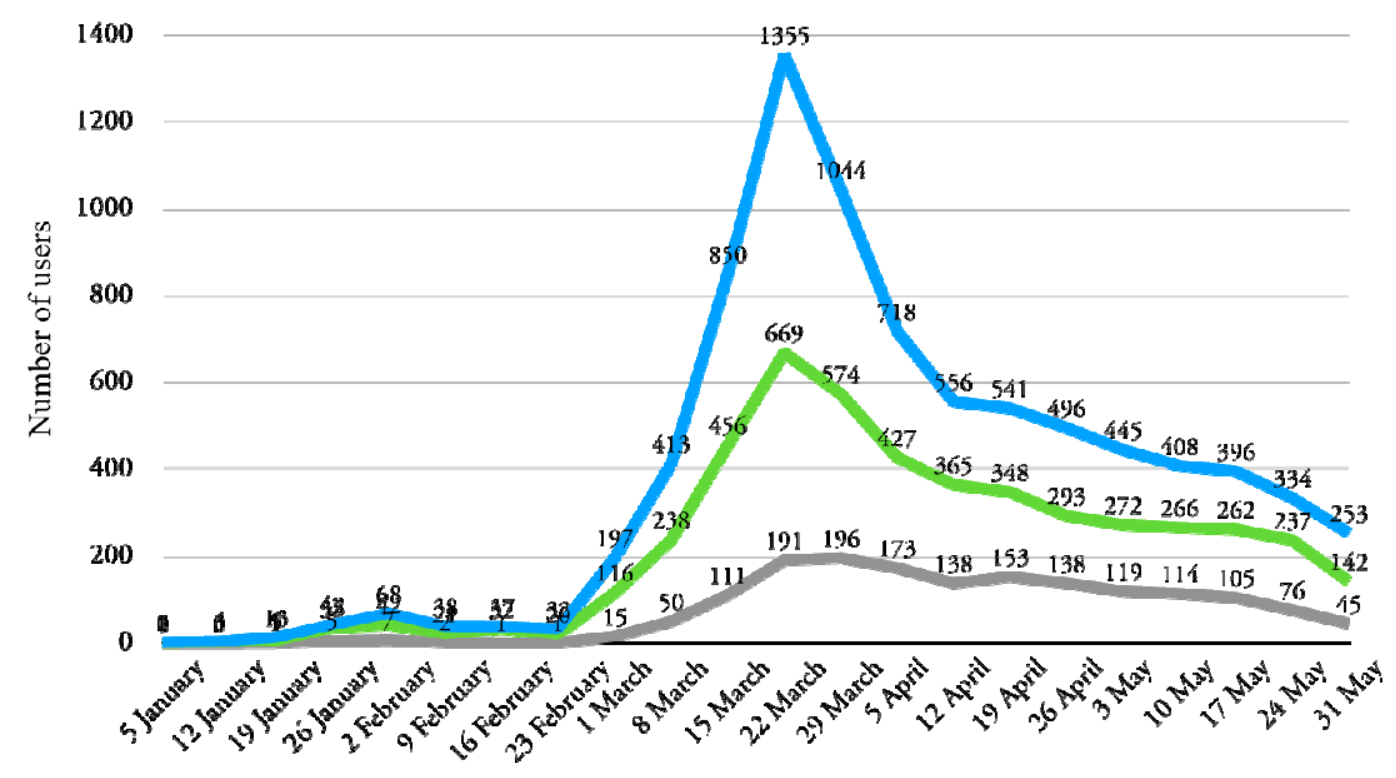


medRxiv preprint doi: https://doi.org/10.1101/2020.12.14.20248155; this version posted December 16, 2020. The copyright holder for this preprint (which was not certified by peer review) is the author/funder, who has granted medRxiv a license to display the preprint in perpetuity.

It is made available under a CC-BY 4.0 International license .

Investigating mental and physical disorders associated with COVID-19 in online health forums

Table 1: Physical health, mental health and intensive care keywords used to search threads and posts

\begin{tabular}{|l|l|}
\hline Physical COVID-19 symptoms & $\begin{array}{l}\text { chest pain, smell, taste, dry cough, anosmia, } \\
\text { breath* }\end{array}$ \\
\hline Mental health symptoms & $\begin{array}{l}\text { worried, worry, worrying, worries, anxious, } \\
\text { anxiety, feel(s) low, feeling low, depression, } \\
\text { depressed, low mood }\end{array}$ \\
\hline Intensive care terms & $\begin{array}{l}\text { itu, icu, intensive care, intubation, intubated, } \\
\text { ventilated, ventilator, c-pap, ecmo, membrane } \\
\text { oxygenation }\end{array}$ \\
\hline
\end{tabular}

Table 2. Keywords applied to threads containing COVID-19 search terms to investigate physical and mental health diagnoses potentially associated with the COVID-19 pandemic

\begin{tabular}{|l|l|}
\hline Comorbid condition & Search terms \\
\hline Cardiovascular/stroke & $\begin{array}{l}\text { heart, infarct*, bypass, stent, coronary, ablation, } \\
\text { atrial fibrillation, arrhythmia, aortic, cardio*, } \\
\text { blockers, cardiomyopathy, statin(s), pressure, } \\
\text { valve, pacemaker, stroke, ischaemia, ischaemic, } \\
\text { anticoag*, anticoagulants, xarelto, apaxiban, } \\
\text { rivaroxiban, dabigatran }\end{array}$ \\
\hline Cancer & $\begin{array}{l}\text { cancer, chemo, chemotherapy, tumours, } \\
\text { melanoma, leukaemia, radiation, radiotherapy }\end{array}$ \\
\hline Respiratory diseases & $\begin{array}{l}\text { asthma, asthmatic, copd } \\
\text { Mental disorders }\end{array}$ \\
\hline Autoimmune diseases & $\begin{array}{l}\text { anxiety, anxious, depression, depressive, } \\
\text { psychosis, psychotic, bipolar, schizophrenia, } \\
\text { schizoaffective, ocd, ptsd }\end{array}$ \\
\hline Diabetes & $\begin{array}{l}\text { crohns, psoriasis, immunosuppress(ant), lupus, } \\
\text { multiple sclerosis, ms, auto-immune }\end{array}$ \\
\hline denotes a wildcard search & $\begin{array}{l}\text { diabetes, mellitus, insulin, humira, remicade, } \\
\text { metformin }\end{array}$ \\
\hline
\end{tabular}


medRxiv preprint doi: https://doi.org/10.1101/2020.12.14.20248155; this version posted December 16, 2020. The copyright holder for this preprint (which was not certified by peer review) is the author/funder, who has granted medRxiv a license to display the preprint in perpetuity.

It is made available under a CC-BY 4.0 International license .

Investigating mental and physical disorders associated with COVID-19 in online health forums

Table 3: Number of users and posts retrieved from selected online health forums from $1^{\text {st }}$ January 2020 to $31^{\text {st }}$ May 2020

\begin{tabular}{clrr}
\hline Website & Number of users & Number of posts & $\begin{array}{c}\text { Number (\%) of posts } \\
\text { mentioning COVIID-19 }\end{array}$ \\
\hline $\begin{array}{c}\text { HealthUnlocked } \\
\text { (www.healthunlocked.com) } \\
\begin{array}{c}\text { HealthBoards } \\
\text { (www.healthboards.com) } \\
\text { Inspire }\end{array}\end{array}$ & 47,999 & 718,103 & $34,657(4.8 \%)$ \\
(www.inspire.com) & 601 & 3,477 & $127(3.7 \%)$ \\
\hline Total & $\mathbf{5 3 , 1 3 4}$ & 17,854 & $797(4.5 \%)$ \\
\hline
\end{tabular}

${ }^{\mathrm{a}} \mathrm{A}$ user is defined as anyone who posted within the data collection period

Table 4: Number and proportion of COVID-19 related threads and posts contained within COVID-19 related threads that mention a comorbidity

\begin{tabular}{|l|c|c|}
\hline Comorbidity & Number of threads, n (\%) & $\begin{array}{c}\text { Number of posts contained } \\
\text { within threads, } \mathbf{n}(\boldsymbol{\%})^{\mathbf{b}}\end{array}$ \\
\hline No condition of interest & $2,340(70.0 \%)$ & $34,201(76.2 \%)$ \\
\hline Autoimmune disorders & $254(7.6 \%)$ & $2,739(6.1 \%)$ \\
\hline Cancer & $223(6.7 \%)$ & $2,114(4.7 \%)$ \\
\hline Respiratory & $150(4.5 \%)$ & $1,905(4.2 \%)$ \\
\hline Cardiovascular / Stroke & $133(4.0 \%)$ & $1,583(3.5 \%)$ \\
\hline Diabetes & $45(1.3 \%)$ & $295(0.7 \%)$ \\
\hline Mental disorders & $215(6.4 \%)$ & $2,243(5.0 \%)$ \\
\hline
\end{tabular}

${ }^{\text {a }}$ Percentage is calculated as number of mentions of comorbidities/ total threads $(\mathrm{N}=3,342)$.

${ }^{\text {b }}$ Percentage is calculated as number of posts / total posts $(\mathrm{N}=44,894)$

Note: Percentages do not add up to $100 \%$ because some threads contained mentions of more than one comorbidity 


\section{Investigating mental and physical disorders associated with COVID-19 in online health forums}

\section{Supplementary Material}

\section{Methods - Search Terms and Keywords}

\section{Supplementary Table 1. Key to regular expressions}

\begin{tabular}{|l|l|}
\hline[] & One of the characters inside the bracket \\
\hline+ & One or more occurrences of previous character \\
\hline$*$ & Zero or more occurrences of previous character \\
\hline$?$ & Zero or one occurrence of previous character \\
\hline Iw & Any alphanumeric character \\
\hline Is & Any whitespace character \\
\hline
\end{tabular}

Examples:

• 'auto[_ls-]?immune' will match all of "autoimmune", "auto-immune" and "auto immune".

- 'psycho[st]i[sc]' will match both "psychotic" and "psychosis"

• ' 'infarctlw*' will match "infarct", "infarcts", "infarction", "infarctions" and "infarcted"

Matching is case-insensitive. When matching post content or thread titles, keywords have to appear as separate whole words; this requirement is lifted when matching thread URLs. To reduce spurious matches, keywords up to three letters long have to appear in URLs surrounded by underscores $\left(\_\right)$or other non-alphanumeric characters in order to be counted as a match.

Supplementary Table 2. Terms used to determine whether a thread or a post was about Covid; these were applied to both thread titles/URLs and post content

\begin{tabular}{|l|l|}
\hline Covid terms & $\begin{array}{l}\text { 'covid', 'covid-?19', 'coronavirus', 'corona', 'sars- } \\
\text { ?cov-?2', 'sars-?2' } \\
\text { 'shielding', 'pandemilw*', 'vulnerable', } \\
\text { 'quarantined?', 'lockdown', 'distancing', 'isolation', } \\
\text { 'isolating' }\end{array}$ \\
\hline Discarded Covid terms & $\begin{array}{l}\text { 'challenging[_Is]times?', 'difficult[_Is]times?', } \\
\text { 'hard[_Is]times?' }\end{array}$ \\
\hline
\end{tabular}


medRxiv preprint doi: https://doi.org/10.1101/2020.12.14.20248155; this version posted December 16, 2020. The copyright holder for this preprint (which was not certified by peer review) is the author/funder, who has granted medRxiv a license to display the preprint in perpetuity.

It is made available under a CC-BY 4.0 International license .

Investigating mental and physical disorders associated with COVID-19 in online health forums:

Supplementary Material

\section{Supplementary Table 3. Terms used to search post content only}

\begin{tabular}{|l|l|}
\hline Mental health symptoms & $\begin{array}{l}\text { 'worried', 'worry', 'worrying', 'worries', 'anxious', } \\
\text { 'anxiety', 'feel[_Is]low', 'feeling[_Is]low', } \\
\text { 'depression', 'depressed', 'low[_Is]mood' }\end{array}$ \\
\hline Intensive care terms & $\begin{array}{l}\text { 'itu', 'icu', 'intensive[_Is]care', 'intubation', } \\
\text { 'intubated', 'ventilated', 'ventilator', 'c-?pap', 'ecmo', } \\
\text { 'membrane[_Is]oxygenation' }\end{array}$ \\
\hline Physical Covid symptoms & $\begin{array}{l}\text { 'chest[_Is]pain', 'smell', 'taste', 'dry[_Is]cough', } \\
\text { 'anosmia', 'breathe?', 'breathing' }\end{array}$ \\
\hline
\end{tabular}

\section{Supplementary Table 4. Keywords applied to thread titles/URLs together with Covid terms to determine threads concerning Covid comorbidities}

\begin{tabular}{|l|l|}
\hline Comorbid condition & Search terms \\
\hline Heart/Stroke & $\begin{array}{l}\text { 'heart', 'infarctlw*', 'bypass', 'stent', 'coronary', } \\
\text { 'ablation', 'a-?fib', 'af', 'arrhythmia', 'aortic', 'cardio', } \\
\text { 'blockers', 'cardiom[yi] pathy', 'statins?', 'pressure', } \\
\text { 'valve', 'pacemaker', 'stroke', 'ischa?emia', } \\
\text { 'ischa?emic', 'anticoag', 'anticoagulants?', 'xarelto', } \\
\text { 'apaxiban', 'rivaroxiban', 'dabigatran' }\end{array}$ \\
\hline Cancer & $\begin{array}{l}\text { 'cancer', 'chemo', 'chemotherapy', 'tumou?rs?', } \\
\text { 'melanoma', 'leuka?emia', 'radiation', 'radiotherapy' }\end{array}$ \\
\hline Respiratory diseases & $\begin{array}{l}\text { 'asthma', 'asthmatic', 'copd' } \\
\text { Mental (health) disorders }\end{array}$ \\
$\begin{array}{l}\text { 'anxiety', 'anxious', 'depression', 'depressive', } \\
\text { 'psycho[st]i[sc]', 'bipolar', 'schizophrenia', } \\
\text { 'schizoaffective', 'ocd', 'ptsd' }\end{array}$ \\
\hline Autoimmune diseases & $\begin{array}{l}\text { 'crohns', 'psoriasis', 'immunosuppress } \\
\text { r'multiple[_ls]sclerosis', 'ms', 'auto[_ls-]?immune' }\end{array}$ \\
\hline Diabetes & $\begin{array}{l}\text { 'diabetlw+', 'mellitus', 'insulin', 'humira', } \\
\text { 'remicade', 'metformin' }\end{array}$ \\
\hline
\end{tabular}


medRxiv preprint doi: https://doi.org/10.1101/2020.12.14.20248155; this version posted December 16, 2020. The copyright holder for this preprint (which was not certified by peer review) is the author/funder, who has granted medRxiv a license to display the preprint in perpetuity.

It is made available under a CC-BY 4.0 International license .

Investigating mental and physical disorders associated with COVID-19 in online health forums: Supplementary Material

Supplementary Table 5. Term incidence of keywords used to scan thread titles/URLs for the observation period (January $1^{\text {st }}-$ May $31^{\text {st }} 2020$ ) vs a control period (September $1^{\text {st }}-$ December $31^{\text {st }} 2019$ )

\begin{tabular}{|c|c|c|c|}
\hline \multirow[t]{2}{*}{ Keyword } & \multicolumn{2}{|c|}{ Term incidence } & \multirow[t]{2}{*}{ Included/Excluded? } \\
\hline & $\begin{array}{l}\text { Observation } \\
\text { period (Jan } \\
1^{\text {st }}-\text { May } 31^{\text {st }} \\
\text { 2020) }\end{array}$ & \begin{tabular}{|l|} 
Control \\
period $\left(\right.$ Sep $1^{\text {st }}$ \\
- December \\
31 $^{\text {st }}$ 2019)
\end{tabular} & \\
\hline covid & 1395 & 0 & Included \\
\hline covid-?19 & 1205 & 0 & Included \\
\hline coronavirus & 859 & 0 & Included \\
\hline corona & 1140 & 14 & Included \\
\hline sars-?cov-?2 & 7 & 0 & Included \\
\hline sars-?2 & 0 & 0 & Included \\
\hline shielding & 202 & 0 & Included \\
\hline pandemilw* & 79 & 0 & Included \\
\hline vulnerable & 120 & 3 & Included \\
\hline quarantined? & 54 & 0 & Included \\
\hline lockdown & 207 & 1 & Included \\
\hline distancing & 82 & 0 & Included \\
\hline isolation & 248 & 2 & Included \\
\hline isolating & 82 & 0 & Included \\
\hline challenging[_Is]times? & 7 & 0 & Excluded \\
\hline difficult[_Is]times? & 13 & 5 & Excluded \\
\hline hard[_Is]times? & 22 & 10 & Excluded \\
\hline
\end{tabular}


medRxiv preprint doi: https://doi.org/10.1101/2020.12.14.20248155; this version posted December 16, 2020. The copyright holder for this preprint (which was not certified by peer review) is the author/funder, who has granted medRxiv a license to display the preprint in perpetuity.

It is made available under a CC-BY 4.0 International license .

Investigating mental and physical disorders associated with COVID-19 in online health forums:

Supplementary Material

\section{Methods - Coding Approach}

\section{Figure 1}

\# counting users who post in threads about COVID-19 and also express a specific concern, i.e. mention keywords from a list of search terms (e.g. mental_symptom_terms) for each given week in time period DEFINE count_user_concerns_week

FOR each user

FOR each week in date_range

IF user posted in a COVID-19 thread during week

week)

DEFINE sliding_window $\leftarrow$ (previous, current and next calendar

FOR each post by user

regex(keywords)

IF date of post in sliding_window and post content matches

ENDIF
ENDIF
ENDFOR
ENDFOR

INCREMENT count_user_concerns_week

BREAK \# exit innermost loop

ENDFOR 
medRxiv preprint doi: https://doi.org/10.1101/2020.12.14.20248155; this version posted December 16, 2020. The copyright holder for this preprint (which was not certified by peer review) is the author/funder, who has granted medRxiv a license to display the preprint in perpetuity.

It is made available under a CC-BY 4.0 International license .

Investigating mental and physical disorders associated with COVID-19 in online health forums:

Supplementary Material

\section{Tables 1 and 2}

DEFINE

websites

covid_terms

pandemic_terms

symptom_terms

intensive_care_terms

mental_symptom_terms

mental_drug_terms

comorbidity_terms

date_range $\longleftarrow$ January $1^{\text {st }}-$ May $31^{\text {st }} 2020$

\# list of online health forums

\# list of COVID-19 terms

\# list of pandemic terms

\# list of physical COVID-19 symptoms

\# list of intensive care terms

\# list of mental health symptoms

\# list of drugs for mental illnesses

\# list of comorbid conditions

\# time period

\section{FUNCTION regex}

INPUT list of keywords from a list of search terms

OUTPUT compiled regex for text containing any of the keywords in the list ENDFUNCTION

\section{Table 3, Supplementary Figure 1}

\# counting posts for each given week in time period

DEFINE count_post_week

FOR each website in websites

FOR each post on website

FOR week in date_range

IF date of post is in week

INCREMENT count_post_week

\section{ENDIF}

\section{ENDFOR}

\section{ENDFOR}

\section{ENDFOR}

\# computing total number of posts

COMPUTE count_post_all as sum of count_post_week over date_range 
medRxiv preprint doi: https://doi.org/10.1101/2020.12.14.20248155; this version posted December 16, 2020. The copyright holder for this preprint (which was not certified by peer review) is the author/funder, who has granted medRxiv a license to display the preprint in perpetuity.

It is made available under a CC-BY 4.0 International license .

Investigating mental and physical disorders associated with COVID-19 in online health forums:

Supplementary Material

\section{Supplementary Figure 2}

\# counting posts mentioning keywords from a list of search terms (e.g. covid_terms) for each given week in time period

DEFINE count_relevant_post_week

FOR each website in websites

FOR each post on website

FOR week in date_range

IF date of post is in week AND post content matches regex(keywords)

INCREMENT count_relevant_post_week

\section{ENDFOR}

\section{ENDFOR}

\section{ENDFOR}

\# Note: To assess the specificity of search terms, we looked for matches before $1^{\text {st }}$ January 2020 , i.e. similar to the above with date_range $\leftarrow<1^{\text {st }}$ January 2020

\# computing relative frequency of posts mentioning keywords from a list of search terms (e.g. covid_terms) for each given week in time period

COMPUTE ratio of count_relevant_post_week to count_post_week 
medRxiv preprint doi: https://doi.org/10.1101/2020.12.14.20248155; this version posted December 16, 2020. The copyright holder for this preprint (which was not certified by peer review) is the author/funder, who has granted medRxiv a license to display the preprint in perpetuity.

It is made available under a CC-BY 4.0 International license .

Investigating mental and physical disorders associated with COVID-19 in online health forums:

Supplementary Material

\section{Supplementary Figure 3}

\# counting active threads about COVID-19 for each given week in time period

DEFINE count_covid_thread

FOR each website in websites

FOR each thread on website

IF thread title or URL matches regex(keywords from covid_terms)

\# date of first and last posts, respectively

DEFINE active_period $\leftarrow$ (thread.start_date, thread.end_date)

FOR week in date_range

IF week is in active_period \# thread is active

INCREMENT count_covid_thread

ENDFOR

\section{ENDIF}

ENDIF

ENDFOR

ENDFOR

\section{Supplementary Figure 4}

\# counting users who post for the first time for each given week in time period

DEFINE count_first_time_user

FOR each user

FOR week in date_range

IF date of user's first post is in week

INCREMENT count_first_time_user

\section{ENDFOR}

\section{ENDFOR}

\section{ENDIF}

\# counting users whose first post is about COVID-19 for each given week in time period DEFINE count_covid_first_time_user

FOR each user

FOR week in date_range

IF date of user's first post is in week AND post content matches

regex(keywords from covid_terms)

INCREMENT count_covid_first_time_user

\section{ENDFOR}

\section{ENDFOR}

\# computing percentage of users whose first post is about COVID-19 for each given week in time period

COMPUTE percentage of count_covid_first_time_user in count_first_time_user 
medRxiv preprint doi: https://doi.org/10.1101/2020.12.14.20248155; this version posted December 16, 2020. The copyright holder for this preprint (which was not certified by peer review) is the author/funder, who has granted medRxiv a license to display the preprint in perpetuity.

It is made available under a CC-BY 4.0 International license .

Investigating mental and physical disorders associated with COVID-19 in online health forums:

Supplementary Material

Table 4

\# counting threads about a comorbid condition within threads about COVID-19

DEFINE count_comorbid_condition_thread

FOR each COVID-19 thread \# see code for Supplementary Figure 3

IF thread title or URL matches regex(keyword (i.e. condition) from comorbidity_terms)

\author{
INCREMENT count_comorbid_condition_thread \\ ENDIF
}

ENDFOR

\# computing ratio of threads about a comorbid condition to threads about COVID-19

COMPUTE ratio of count_comorbid_condition_thread to sum of count_covid_thread over date_range

\# computing number of posts in threads about a comorbid condition

COMPUTE count_comorbid_condition_post as sum of number of posts in threads about a comorbid condition

\# computing ratio of posts in threads about a comorbid condition to posts in threads about COVID-19

COMPUTE ratio of count_comorbid_condition_post to sum of number of posts in threads about COVID-19 
medRxiv preprint doi: https://doi.org/10.1101/2020.12.14.20248155; this version posted December 16, 2020. The copyright holder for this preprint (which was not certified by peer review) is the author/funder, who has granted medRxiv a license to display the preprint in perpetuity.

It is made available under a CC-BY 4.0 International license.

Investigating mental and physical disorders associated with COVID-19 in online health forums: Supplementary Material

\section{Supplementary Figure 1: Weekly number of posts on any topic in the period January} 2020 to May 2020

- HealthUnlocked
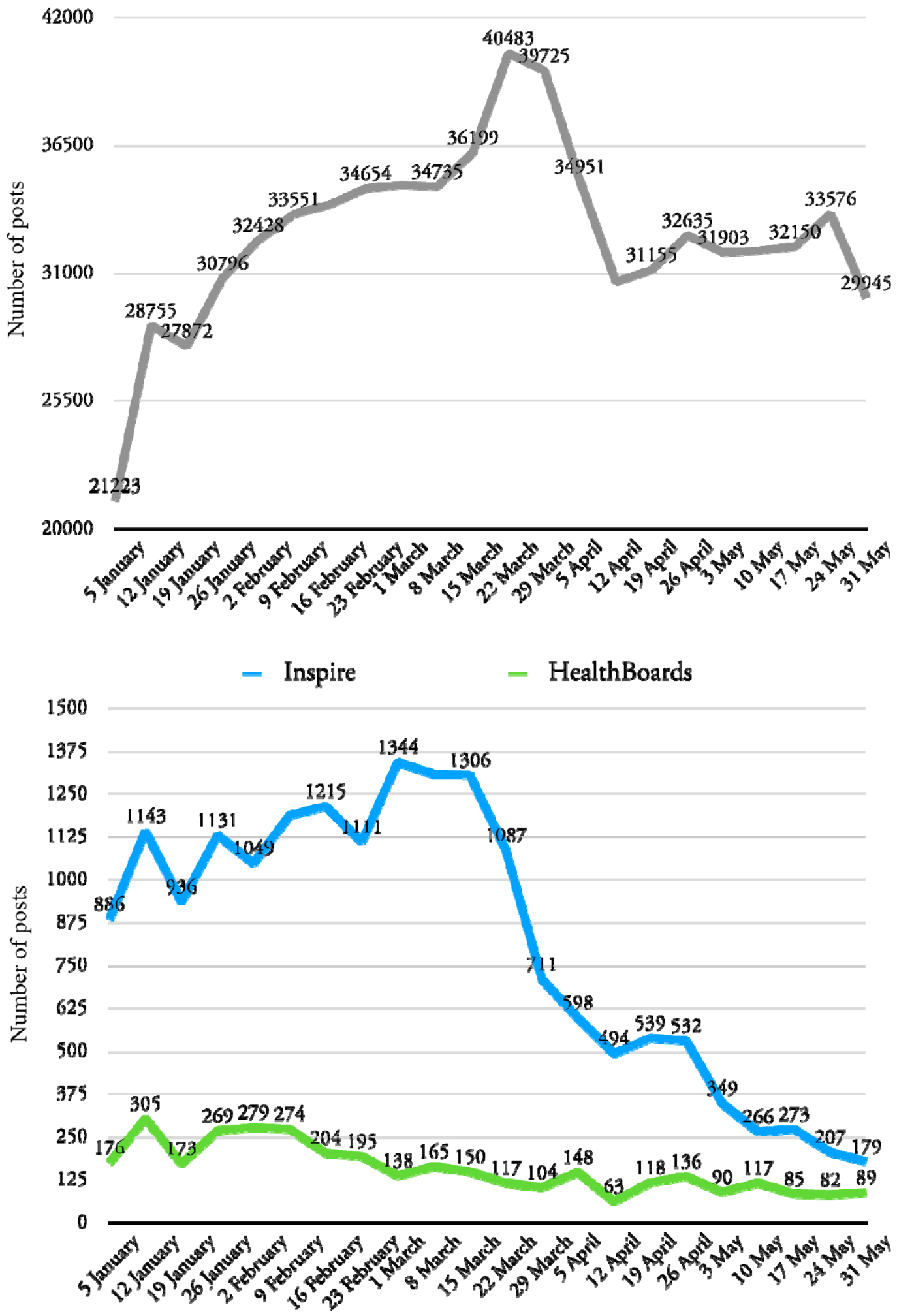
medRxiv preprint doi: https://doi.org/10.1101/2020.12.14.20248155; this version posted December 16, 2020. The copyright holder for this preprint (which was not certified by peer review) is the author/funder, who has granted medRxiv a license to display the preprint in perpetuity.

It is made available under a CC-BY 4.0 International license .

Investigating mental and physical disorders associated with COVID-19 in online health forums: Supplementary Material

Supplementary Figure 2: Percentage of COVID-19 related posts relative to all weekly posts

$$
\text { - Inspire } \quad-\text { HealthBoards } \quad-\text { HealthUnlocked }
$$

\section{$25 \%$}

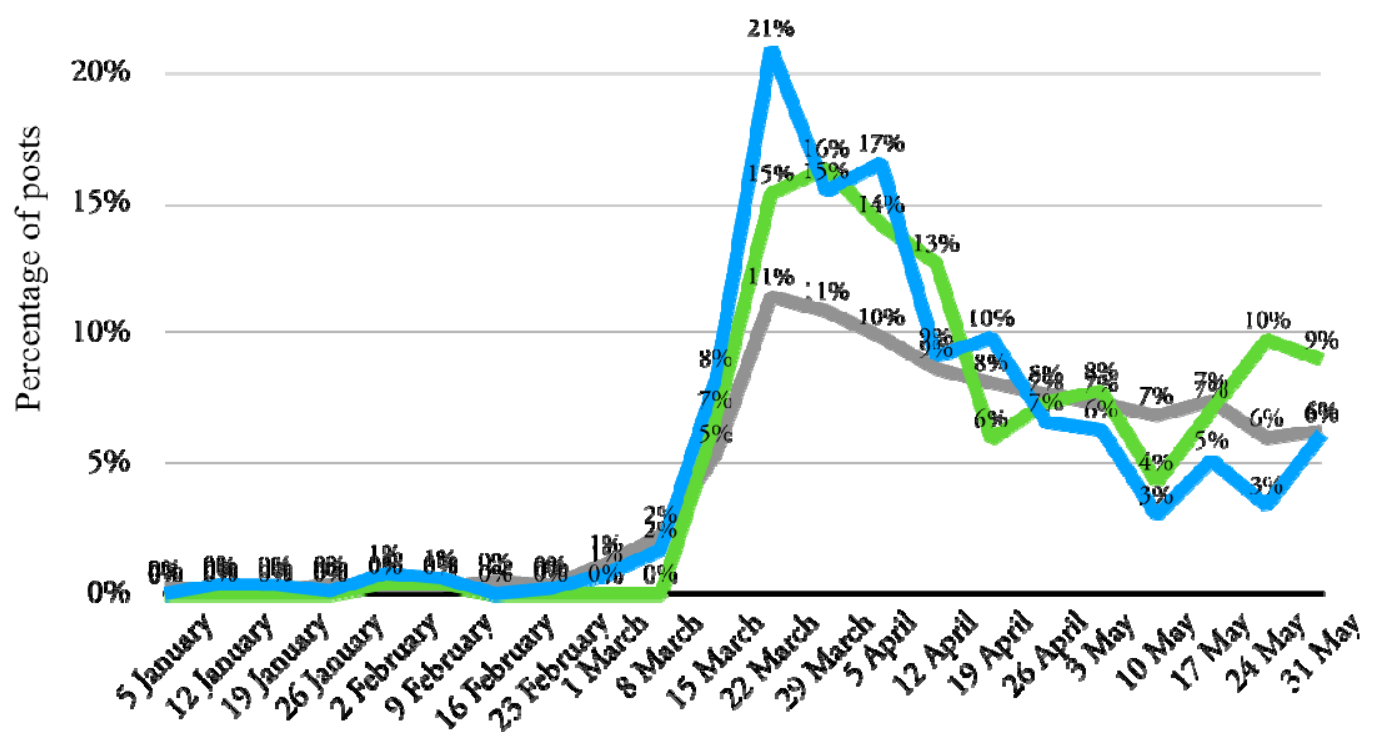


medRxiv preprint doi: https://doi.org/10.1101/2020.12.14.20248155; this version posted December 16, 2020. The copyright holder for this preprint (which was not certified by peer review) is the author/funder, who has granted medRxiv a license to display the preprint in perpetuity.

It is made available under a CC-BY 4.0 International license .

Investigating mental and physical disorders associated with COVID-19 in online health forums: Supplementary Material

Supplementary Figure 3: Maximum number of COVID-19 related threads active in each given week

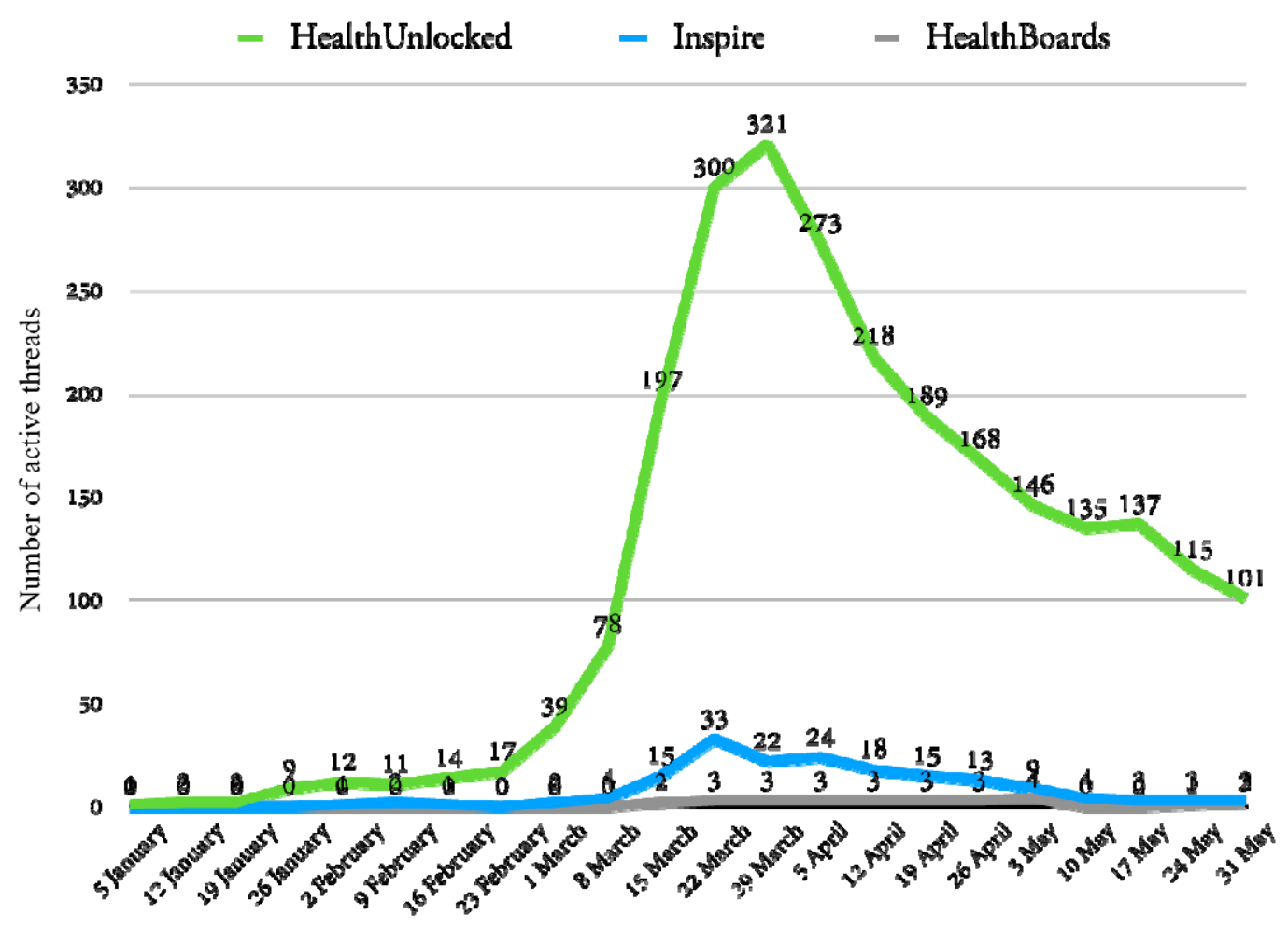

A thread is considered closed and therefore no longer active when there are no further posts from that week within the data collection period (up until $31^{\text {st }}$ May 2020). Note that this does not rule out the possibility of a thread becoming reactivated past this date. 
medRxiv preprint doi: https://doi.org/10.1101/2020.12.14.20248155; this version posted December 16, 2020. The copyright holder for this preprint (which was not certified by peer review) is the author/funder, who has granted medRxiv a license to display the preprint in perpetuity.

It is made available under a CC-BY 4.0 International license .

Investigating mental and physical disorders associated with COVID-19 in online health forums: Supplementary Material

Supplementary Figure 4: Proportion of users whose very first post was in a COVID-19 related thread, given weekly

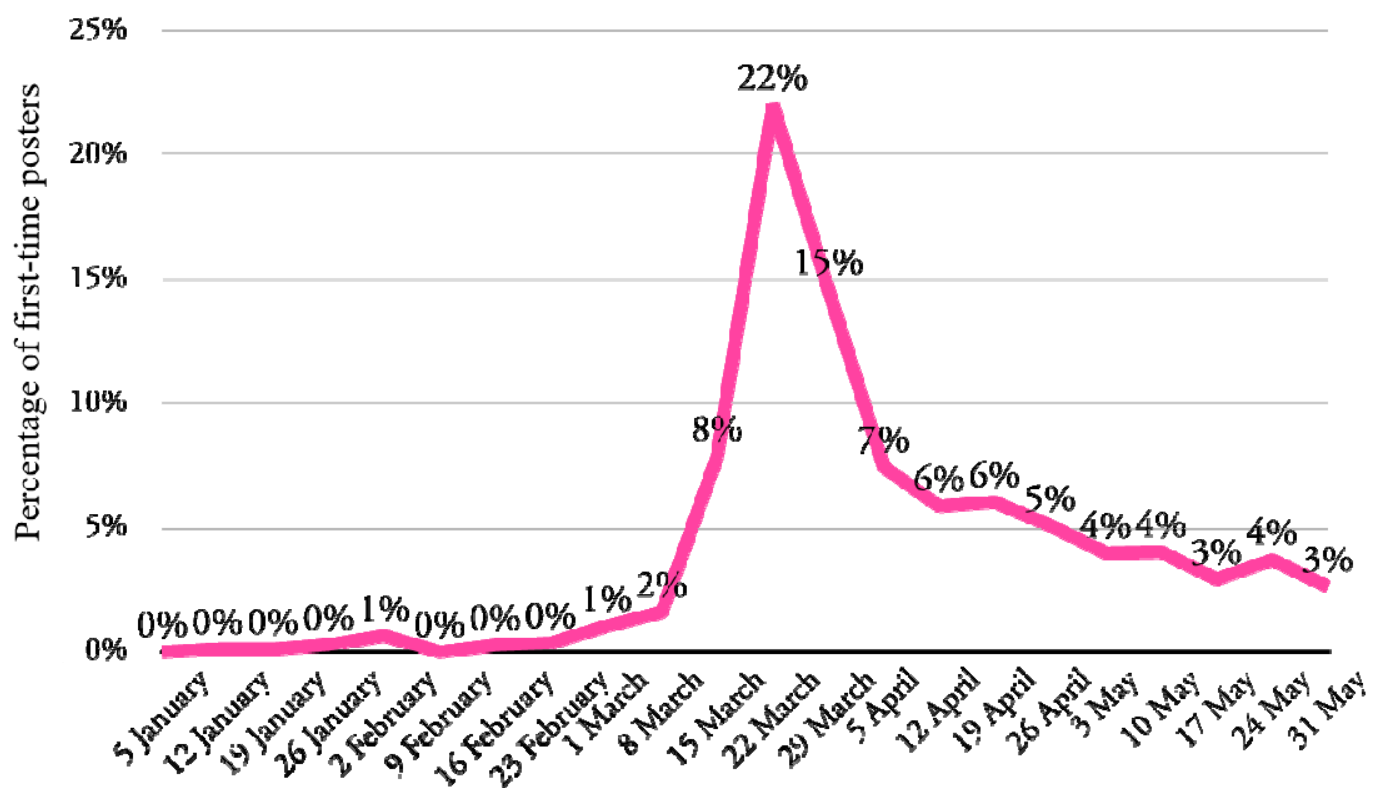

